\title{
Implementation of Community-led Total Sanitation and Hygiene Approach on the Prevention of Diarrheal Disease in Kersa District, Jimma Zone Ethiopia
}

\author{
Negasa Eshete ${ }^{1}$, Abebe Beyene ${ }^{2}$, Gudina Terefe ${ }^{2}$ \\ ${ }^{1}$ Department of Public Health, Dilla University, Dilla, Ethiopia \\ ${ }^{2}$ Department of Environmental Health sciences, Jimma University, Jimma, Ethiopia
}

Email address:

yeroosaan@gmail.com (N. Eshete), abebebh2003@yahoo.com (A. Beyene), guditerefe@yahoo.com (G. Terefe)

\section{To cite this article:}

Negasa Eshete, Abebe Beyene, Gudina Terefe. Implementation of Community-led Total Sanitation and Hygiene Approach on the Prevention of Diarrheal Disease in Kersa District, Jimma Zone Ethiopia. Science Journal of Public Health. Vol. 3, No. 5, 2015, pp. 669-676.

doi: $10.11648 /$ j.sjph.20150305.22

\begin{abstract}
Introduction: Lack of access to safe water supply and inadequate sanitation and unsafe hygiene practices can cause diarrheal diseases. It is believed that implementation of Community-led Total Sanitation and Hygiene (CLTSH) will significantly reduce the risk of diarrheal diseases. Objective: To assess the Community-led Total Sanitation and Hygiene approach on the prevention of diarrheal disease in Kersa District of Jimma Zone, Southwest Ethiopia. Methods: A cross sectional study was conducted in Kersa District of Jimma Zone, Southwest Ethiopia from December 03, 2012 to January 11, 2013. The study subjects were randomly selected 423 households from CLTSH implemented and 423 households where CLTSH none implemented kebeles. Data was collected through interview and observation then data obtained was analyzed with SPSS version 16.0. Result: The study showed that the extent of latrine coverage and utilization in CLTSH implemented was greater than that of CLTSH non-implemented kebeles. In this study the occurrence of diarrhea was statistically associated with the extent of latrine utilization in the bivariate analysis in the CLTSH non-implemented kebeles [OR: 9.64, 95\%CI: (5.11-18.19)] but the significant was disappeared in the multivariate analysis. Study showed that hand-washing facility near the latrine in CLTSH implemented (73.06\%) was greater than that of CLTSH non-implemented kebeles $(72.58 \%)$. But the risk of diarrhea was statistically associated with hand washing facility only in CLTSH non-implemented kebeles in bivariate and multivariate analysis. Conclusion: in the study the diarrhea prevalence is less in CLTSH implemented than the non implemented kebeles. So it is possible to reduce diarrheal disease through implementation of CLTSH approach. Health-workers and local authorities must pay special emphasis to improve these conditions.
\end{abstract}

Keywords: CLTSH Implementation, Diarrhea Prevention, Cross-sectional Study, Ethiopia

\section{Introduction}

Inadequate and unsafe water, poor sanitation, and unsafe hygiene practices are the main causes of diarrhea. Diarrheal diseases constitute a major burden of disease in the world, especially in low- and middle-income countries [1]. In 2004, the disease was the third leading cause of death in low-income countries, causing $6.9 \%$ of deaths overall [2].

In African countries including Ethiopia, each child on average suffers from five episodes of diarrhea per year while the two-week prevalence ranges from 10 to $40 \%$ in different parts of Ethiopia. Diarrheal diseases have persistently been the first or the second causes of visits to health units in the country [3].
Lack of access to clean water, and poor hygiene practices such as open defecation and lack of hand-washing afterwards, are leading causes of diarrhea [4]

Report of Ethiopia Demographic and Health Survey of 2011 also showed that about $46 \%$ of households in the Ethiopia have access to non-improved source of drinking water and $82 \%$ of households use non-improved toilet facilities; of these, $38 \%$ of households have no toilet facility $[5]$.

The Government of Ethiopia and partners like UNICEF, Plan International Ethiopia, WSP-AF, and USAID's Hygiene Improvement Project (HIP) are applying tireless efforts to reverse the situation of health risks associated with the current state of hygiene and sanitation in the country. One of the 
effective and efficient approaches to upscale sanitation and hygiene is Community-Led Total Sanitation (CLTS); now called community-led total sanitation and hygiene (CLTSH) [6].

Even the implementation was started in different parts of Ethiopia; the assessment of CLTSH approach on the control of diarrheal disease was not assessed, particularly in the study area. So, the objective of this study is to assess the implementation of Community-led Total Sanitation and Hygiene approach on the prevention of diarrheal disease in Kersa District, Jimma zone Ethiopia.

\section{Methods and Materials}

\subsection{Study Design and Population}

A community based cross-sectional study design was conducted from December 2012-January 2013 in Kersa District, Jimma zone Ethiopia. Randomly selected households living in six selected kebeles of Kersa District were included in the study. The representative person of the family (household heads or spouses) and live for more than 6 months in the study area was included. The sample size was calculated using two population proportion formula. By using proportion of households exposed to diarrheal disease $50 \%$ for two study groups (there is no similar study), 95\% confidence level, $5 \%$ tolerable margin of error and possible non-response rate of $10 \%$, the final sample size was 846 . The study subjects were selected by multi stage sampling procedure, where first the kebeles divided in to CLTSH implemented \& none-implemented kebeles then 3 kebeles were selected from each total kebeles by simple random sampling technique using lottery method. Then, to draw a sampling frame the total numbers of households in the selected kebeles were obtained from local authority of that kebele. The study households were distributed proportionally to population size (number of households) in the kebeles. Systematic random sampling (every $8^{\text {th }}$ households) from the selected households in the kebeles was included for the study. Data was collected using a structured questionnaire prepared by reviewing previously done studies and other materials related to the topic. To maintain the quality of data, training was given for data collectors. Regular and continues follow up was made by the principal investigator to monitor quality of the data collection process and every filled checklist was checked on daily basis and feedbacks were given to data collectors.

\subsection{Study Variables}

Diarrheal disease prevalence was the dependent variable and Socio-economic factor (age, sex, income, occupation, educational status \& religion), Environmental factors (water source, water source protection, availability of latrine, latrine lid, hand washing near latrine \& way of waste disposal) and Behavioral factors (Water storage , time of hand washing, Way of drinking water drawing from storage, latrine utility, open defecation, hand washing after defecation) were independent variables of the study.

\subsection{Data Processing and Data Analysis}

The collected data were edited, entered into a computer by using SPSS version 16.00 and analyzed. Binary logistic regression was done to determine whether the independent variables can predict the outcome variable. The result of the odd ratio was used for interpretation of strength of prediction of the independent variable to the outcome. The finding from all analysis was summarized and presented by graphs, tables and other summery measures. For all statistical significance tests, the cut- off value set will be $\mathrm{p}<0.05$ with CI of 95

\subsection{Ethical Consideration}

Ethical approval was obtained from Jimma University College of Public Health and Medical Science, Department of Environmental Health Sciences \& Technology; informed permission was also obtained from Kersa District \& each study subject prior to the interview after the purpose of the study was explained to respondent.

\section{Result}

\subsection{Social Demographic Characteristics of Respondents}

A total of eight hundred forty six households were included in this study. Out of these households, four hundred twenty three $(50 \%)$ from CLTSH implemented kebeles while the remains were from CLTSH none implemented kebeles. There was no non-response found during the data collection. One hundred eighty four $(43.50 \%)$ and one hundred thirty four $(31.68 \%)$ of the respondents were wives in CLTSH implemented and non-implemented kebeles respectively (Table 1).

\subsection{Environmental Characteristics of Diarrhea}

One hundred ninety three $(45.63 \%)$ households in CLTSH implemented kebeles \& three hundred seventy three (88.20\%) households in CLTSH non-implemented kebeles used spring as the main source of drinking water. Three hundred eight (72.81\%) \& two hundred twenty nine $(54.10 \%)$ of households in CLTSH implemented and non-implemented kebeles used protected source as the main source of water respectively. Regardless of the distance of water source, three hundred thirty one $(78.25 \%)$ households in CLTSH implemented kebeles and three hundred forty eight $(82.30 \%)$ households in CLTSH none implemented kebeles got water in a less than one kilometer walking distance from their home.

Three hundred eighty seven $(91.49 \%)$ households in CLTSH implemented kebeles and three hundred seventy two (87.90\%) households in CLTSH none implemented kebeles had latrine facility. All (100\%) types of available latrines were traditional pit latrines. One hundred four $(23.87 \%)$ of latrine in CLTSH approach implemented kebeles and two hundred ten (56.42\%) of latrine in CLTSH approach none implemented kebeles were do not have cover for latrine drop-hole. About two hundred thirty four $(60.47 \%)$ of latrines in CLTSH implemented kebeles and one hundred ninety two (51.45\%) of 
latrines in CLTSH none implemented kebeles were less than six meter far away from kitchen. One hundred four(26.94\%) households CLTSH implemented kebeles \& one hundred two
(27.42\%) households in CLTSH none implemented kebeles with latrine had no any kind of hand washing facilities. (Table 2)

Table 1. Socioeconomic characteristics of the study households of the study site, Kersa District, January 2013.

\begin{tabular}{|c|c|c|c|}
\hline \multirow{2}{*}{ Variable } & & \multicolumn{2}{|c|}{ Community-led Total Sanitation and Hygiene approach } \\
\hline & & Implemented kebeles No (\%) & Non-Implemented kebeles No (\%) \\
\hline \multirow{3}{*}{ Status of the respondent } & Husband & $143(33.81)$ & $185(43.74)$ \\
\hline & Wife & $184(43.50)$ & $134(31.68)$ \\
\hline & Others & $96(22.70)$ & $104(24.59)$ \\
\hline \multirow{3}{*}{ Age of respondent } & $18-25$ & $154(36.41)$ & $168(39.72)$ \\
\hline & $25-40$ & $235(55.56)$ & $186(43.97)$ \\
\hline & $>40$ & $34(8.04)$ & $69(16.31)$ \\
\hline \multirow{3}{*}{ Religion } & Orthodox & $2(0.47)$ & $93(21.99)$ \\
\hline & Protestant & 0 & $8(1.89)$ \\
\hline & Muslim & $421(99.53)$ & $322(76.12)$ \\
\hline \multirow{4}{*}{ Ethnicity } & Oromo & $421(99.53)$ & $415(98.11)$ \\
\hline & Amhara & 0 & $4(0.95)$ \\
\hline & Kefa & 0 & $4(0.95)$ \\
\hline & Others & $2(0.47)$ & 0 \\
\hline \multirow{3}{*}{ Family size } & $1-3$ & $94(22.22)$ & $97(22.93)$ \\
\hline & $4-6$ & $231(54.61)$ & $177(41.84)$ \\
\hline & $>7$ & $98(23.17)$ & $149(35.22)$ \\
\hline \multirow{3}{*}{ No of children aged under 5} & 1 & $171(40.43)$ & $202(47.75)$ \\
\hline & 2 and above & $166(39.24)$ & $86(20.33)$ \\
\hline & None & $86(20.33)$ & $135(31.91)$ \\
\hline \multirow{3}{*}{$\begin{array}{l}\text { Education status of the } \\
\text { respondent }\end{array}$} & Illiterate & $261(61.70)$ & $244(57.68)$ \\
\hline & Literate & $162(38.30)$ & $179(42.32)$ \\
\hline & Governmental employee & $10(2.36)$ & $15(3.55)$ \\
\hline \multirow{2}{*}{ Occupation of the Household } & Merchant & $38(8.98)$ & $66(15.60)$ \\
\hline & Farmer & $373(88.18)$ & $340(80.38)$ \\
\hline \multirow{5}{*}{ Monthly income } & Daily laborer & $2(0.47)$ & $2(0.47)$ \\
\hline & $<350$ & $10(2.36)$ & $193(45.63)$ \\
\hline & $350-550$ & $38(8.98)$ & $82(19.39)$ \\
\hline & $551-750$ & $373(88.18)$ & $21(4.96)$ \\
\hline & $>750$ & $2(0.47)$ & $127(30.02)$ \\
\hline
\end{tabular}

Table 2. Environmental conditions of the study households of the study site, Kersa District, January, 2013.

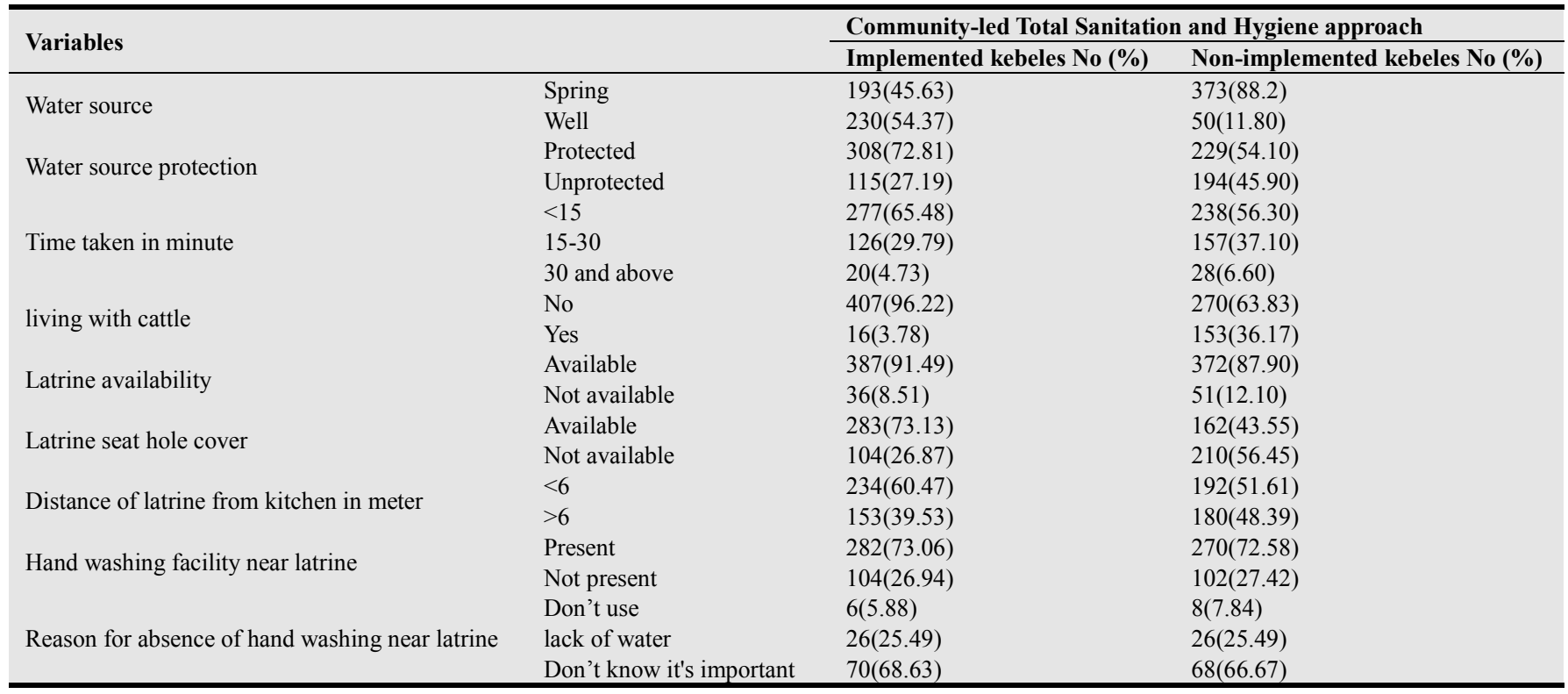

From a total of 846 households whose responses were obtained, thirty $(8.24 \%)$ in the CLTSH implemented and seventy eight $(18.28 \%)$ in the CLTSH non-implemented explained that they disposed wastes in open dump in the compound where as about two hundred sixty one (61.70\%) households in the CLTSH implemented and 2two hundred twenty three $(52.5 \%)$ households in the CLTSH non-implemented open pits (Figure 1). 


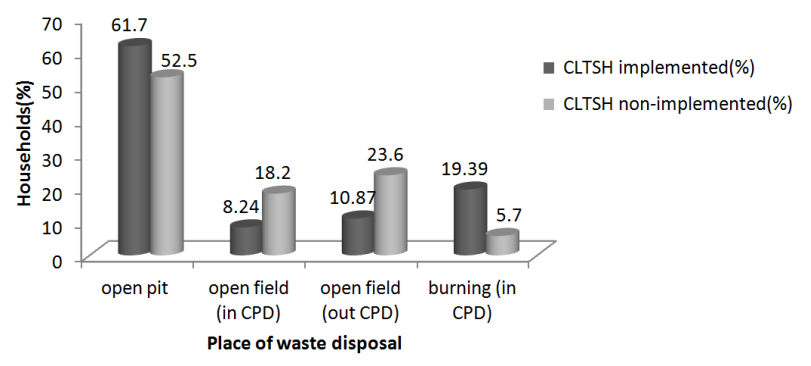

Figure 1. Solid waste disposal methods of households of the study area, Kersa District, January 2013.

\subsection{Behavioral Factors of Diarrhea}

Two hundred forty three $(57.45 \%)$ respondents of CLTSH implemented kebeles and two hundred sixteen (51.10\%) respondents of CLTSH non-implemented kebeles were treat their drinking water if the source is other than protected source by boiling, filtering and adding water guard. Three hundred seventy nine $(89.60 \%)$ of households of CLTSH implemented kebeles and three hundred twenty two (76.10\%) of respondents of CLTSH non-implemented kebeles were store their water in jerry can. Forty four $(10.40 \%)$ of the CLTSH implemented and one hundred one $(21.90 \%)$ of CLTSH none-implemented kebeles households practiced dipping method to draw water from the container. Three hundred twenty seven $(77.30 \%)$ in CLTSH implemented kebeles and two hundred ninety four $(69.50 \%)$ of CLTSH none implemented kebeles households got less than $10 \mathrm{~L} / \mathrm{C} /$ day average water consumption. The average water consumption of the approach implemented and none implemented kebeles were $8.05 \mathrm{~L} / \mathrm{C} /$ day \& $7.27 \mathrm{~L} / \mathrm{C} /$ day respectively.

Table 3. Behavioral conditions of the study households of the study site, Kersa District, January 2013.

\begin{tabular}{|c|c|c|c|}
\hline \multirow{2}{*}{ Variables } & & \multicolumn{2}{|c|}{ Community-led Total Sanitation and Hygiene approach } \\
\hline & & Implemented kebeles No (\%) & Non-implemented kebeles No (\%) \\
\hline \multirow{2}{*}{ Water treatment } & Yes & $243(57.45)$ & $216(51.1)$ \\
\hline & No & $180(42.55)$ & 207(48.9) \\
\hline \multirow{3}{*}{ method of treatment } & Boiling & $181(74.49)$ & $32(14.55)$ \\
\hline & Filtering & $24(9.88)$ & $162(73.64)$ \\
\hline & Others & $38(15.64)$ & $26(11.82)$ \\
\hline \multirow{2}{*}{ Material used for water storage } & jerry can & $379(89.60)$ & $322(76.1)$ \\
\hline & Pail & $12(2.84)$ & $22(5.2)$ \\
\hline \multirow{2}{*}{$\begin{array}{l}\text { washing storage equipment before } \\
\text { collection }\end{array}$} & Yes & $407(96.22)$ & $421(99.5)$ \\
\hline & No & $16(3.78)$ & $2(0.5)$ \\
\hline \multirow{2}{*}{ Method of drawing water from storage } & Pouring & $379(89.60)$ & $322(76.1)$ \\
\hline & Dipping & $44(10.40)$ & $101(23.9)$ \\
\hline \multirow{2}{*}{$\begin{array}{l}\text { Presence of water storage covers during } \\
\text { survey }\end{array}$} & Yes & $411(97.16)$ & $417(98.6)$ \\
\hline & No & $12(2.84)$ & $6(1.4)$ \\
\hline Average water consumption in $\mathrm{L} /$ per/day & $10-20$ & $96(22.70)$ & $129(30.5)$ \\
\hline \multirow{4}{*}{ Who construct latrine? } & by self & $381(98.45)$ & $366(98.39)$ \\
\hline & kebele leaders & $4(1.03)$ & $2(0.54)$ \\
\hline & primary health workers & $2(0.52)$ & $2(0.54)$ \\
\hline & Others & 0 & $2(0.54)$ \\
\hline \multirow{3}{*}{ Latrine utility } & Rarely & 0 & $31(8.33)$ \\
\hline & Mostly & $5(1.29)$ & $22(5.91)$ \\
\hline & Always & $382(98.71)$ & $319(85.75)$ \\
\hline \multirow{3}{*}{ If no latrine why not } & too expensive & $16(44.44)$ & $34(66.67)$ \\
\hline & nearest toilet here & $14(38.89)$ & $13(25.49)$ \\
\hline & No land to build one & $4(11.11)$ & $4(7.84)$ \\
\hline \multirow{3}{*}{ If no latrine place of defecation } & open field & $15(41.67)$ & $28(54.9)$ \\
\hline & community latrine & $21(58.33)$ & $17(33.3)$ \\
\hline & Others & 0 & $6(11.8)$ \\
\hline \multirow{2}{*}{ Hand washing after defecation } & Yes & $385(99.48)$ & $357(95.97)$ \\
\hline & No & $2(0.52)$ & $15(4.03)$ \\
\hline \multirow{2}{*}{$\begin{array}{l}\text { Knowledge of importance of hand } \\
\text { washing }\end{array}$} & Yes & $421(99.53)$ & $414(97.9)$ \\
\hline & No & $2(0.47)$ & $9(2.1)$ \\
\hline \multirow{2}{*}{ Time of hand washing } & Mixed practices & $10(2.36)$ & $54(12.8)$ \\
\hline & At all critical time & $413(97.64)$ & $369(87.2)$ \\
\hline \multirow{2}{*}{ Presence of feces in the latrine } & Yes & $104(26.87)$ & 71(19.09) \\
\hline & No & $283(73.13)$ & $301(80.91)$ \\
\hline \multirow{3}{*}{ Place of children feces disposal } & in the latrine & $347(82.03)$ & $286(67.6)$ \\
\hline & in the open field & $70(16.55)$ & $123(29.1)$ \\
\hline & Others & $6(1.42)$ & $14(3.3)$ \\
\hline \multirow{2}{*}{$\begin{array}{l}\text { Presence of feces in the } \\
\text { compound/around home }\end{array}$} & Yes & $120(28.37)$ & $86(20.3)$ \\
\hline & No & $303(71.63)$ & $337(79.7)$ \\
\hline
\end{tabular}




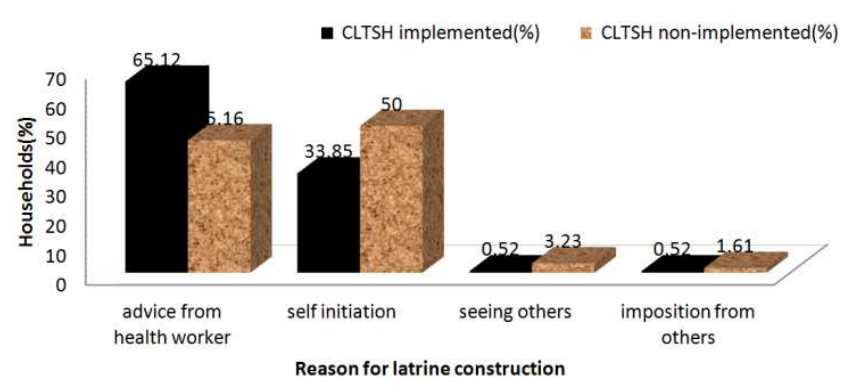

Figure 2. Reasons for latrine construction of the study area, Kersa District, January 2013.

Out of the total 252 households in CLTSH implemented and 268 households in the non-implemented respondents who indicated the availability of latrine; only one hundred thirty one (33.85\%) households in CLTSH implemented and one hundred eight six $(50 \%)$ households in the non-implemented constructed their latrine by self initiation (Figure 2).

In these households the information on diarrheal morbidity was obtained by asking the households/caretaker whether there was diarrheic person in the two-week period. If the members had had diarrhea, the caretaker was asked about action taken during the diarrheal episode. Accordingly, the overall two weeks period prevalence of diarrhea in the CLTSH implemented and CLTSH none implemented kebeles were found to be $18.91 \%$ and $22.22 \%$ respectively and the incidence of diarrhea was $11.82 \%$ in CLTSH implemented and $13.9 \%$ in CLTSH non-implemented kebeles.

Table 4. Health characteristics of the households of the study site, Kersa District, January 2013.

\begin{tabular}{|c|c|c|c|}
\hline \multirow{2}{*}{ Variables } & & \multicolumn{2}{|c|}{ Community-led Total Sanitation and Hygiene approach } \\
\hline & & Implemented kebelesNo (\%) & Non-implemented kebeles No (\%) \\
\hline \multirow{2}{*}{$\begin{array}{l}\text { Diarrhoea in the past two weeks period } \\
\text { (Incidence) }\end{array}$} & Yes & $50(11.82)$ & $59(13.90)$ \\
\hline & No & $373(88.18)$ & $364(86.10)$ \\
\hline \multirow{2}{*}{ Age of diarrheal patient in the past two weeks } & $<5$ & $40(71.43)$ & $44(74.58)$ \\
\hline & $>5$ & $16(28.57)$ & $15(25.42)$ \\
\hline \multirow{2}{*}{$\begin{array}{l}\text { Presence of diarrheal during survey (Point } \\
\text { Prev.) }\end{array}$} & Yes & $30(7.09)$ & $35(8.30)$ \\
\hline & No & 393(92.91) & $388(91.70)$ \\
\hline \multirow{2}{*}{ Age of diarrheal patient in the during survey } & $<5$ & $14(46.67)$ & $25(71.43)$ \\
\hline & $>5$ & $16(53.33)$ & $10(28.57)$ \\
\hline \multirow{2}{*}{$\begin{array}{l}\text { Two weeks period prevalence(Point Prev. + } \\
\text { Incidence) }\end{array}$} & Yes & $80(18.91)$ & $94(22.22)$ \\
\hline & No & $343(81.09)$ & $339(77.78)$ \\
\hline \multirow{3}{*}{ Action taken } & No action taken & $4(6.90)$ & $6(7.69)$ \\
\hline & Take to health institution & $50(86.21)$ & $72(92.31)$ \\
\hline & Take to traditional healer & $4(6.90)$ & 0 \\
\hline
\end{tabular}

\subsection{Factors Associated with Diarrheal Disease}

The association between presences of diarrhea and independent variables was presented in Table 5. In the model, variables which were significantly association in the bivariate analysis were re-evaluated independently controlling for other potential confounders. Hence, most of the variables disappeared and family size, source of water supply, place of waste disposal and detergent used for hand washing after latrine visit in the CLTSH implemented \& family size and presence of hand washing facility near the latrine in the CLTSH non-implemented kebeles were remained to be independent risk factors/predictors of diarrheal morbidity.

Even though some variables were significantly association in the bivariate analysis, their significance disappeared in the multivariate analysis. Time of hand washing which was significantly associated in both CLTSH implemented [OR: 4.25, 95\% CI: (1.16-15.53)] and non-implemented [OR: 6.87, 95\% CI: (3.73-12.66)] kebeles were disappeared in multivariate analysis. Availability of latrine which showed significant association in the bivariate analysis [OR: 9.64, 95\%CI :(5.11-18.19)] also disappeared in the multivariate analysis in CLTSH non-implemented kebeles.

The odds of having diarrhoea in households where waste/refuse was disposed in the Open field (out of the compound) was significantly 3 times higher than the odds in those households that burned in the compound [OR: $3.10,95 \%$ CI: (1.05-9.17)] in CLTSH implemented kebeles and the significance remained appeared in the multivariate analysis in but had no significant association in the multivariate analysis in CLTSH non-implemented kebeles (see table 5).

Table 5. Multivariate regression of the relative effect of variables on the occurrence of diarrhea morbidity, Kersa District, January 2013.

\begin{tabular}{|c|c|c|c|c|c|}
\hline \multirow{3}{*}{ Variables } & & \multicolumn{4}{|c|}{ Community-led Total Sanitation and Hygiene approach } \\
\hline & & \multicolumn{2}{|l|}{ Implemented kebeles } & \multicolumn{2}{|c|}{ Non-implemented kebeles } \\
\hline & & Crude OR(95\% CI) & $\begin{array}{l}\text { Adjusted OR(95\% } \\
\text { CI) }\end{array}$ & Crude OR(95\% CI) & $\begin{array}{l}\text { Adjusted OR(95\% } \\
\text { CI) }\end{array}$ \\
\hline \multirow{3}{*}{ Family size } & $1-3$ & $0.95(0.46-1.96)$ & $0.85(0.37-1.97)$ & $2.08(1.10-3.95)^{*}$ & $0.35(0.12-1.09)$ \\
\hline & $4-6$ & $2.14(1.09-4.19)^{*}$ & $2.13(1.03-4.45)^{*}$ & $1.14(0.62-2.09)$ & $0.27(0.09-0.85)^{*}$ \\
\hline & $>7$ & 1.0 & 1.00 & 1.00 & 1.00 \\
\hline
\end{tabular}




\begin{tabular}{|c|c|c|c|c|c|}
\hline \multirow{3}{*}{ Variables } & & \multicolumn{4}{|c|}{ Community-led Total Sanitation and Hygiene approach } \\
\hline & & \multicolumn{2}{|c|}{ Implemented kebeles } & \multicolumn{2}{|c|}{ Non-implemented kebeles } \\
\hline & & Crude OR(95\% CI) & $\begin{array}{l}\text { Adjusted OR(95\% } \\
\text { CI) }\end{array}$ & Crude OR(95\% CI) & $\begin{array}{l}\text { Adjusted OR(95\% } \\
\text { CI) }\end{array}$ \\
\hline \multirow{3}{*}{$\begin{array}{l}\text { Number of under five } \\
\text { children }\end{array}$} & no child & & & $0.73(0.37-1.45)$ & - \\
\hline & 1 & & & $0.42(0.24-0.74)^{*}$ & - \\
\hline & 2 and above & & & 1.00 & 1.00 \\
\hline \multirow{3}{*}{ Educational status } & Illiterate & & & 1.00 & 1.00 \\
\hline & Literate & & & $1.77(1.08-2.91)^{*}$ & $0.34(0.11-1.06)$ \\
\hline & $<350$ & & & 1.00 & 1.00 \\
\hline \multirow{3}{*}{ Monthly income } & $350-550$ & & & $1.20(0.66-2.18)$ & $2.00(0.63-6.32)$ \\
\hline & $551-750$ & & & $0.50(0.26-0.97)^{*}$ & $1.97(0.48-8.02)$ \\
\hline & $>750$ & & & - & - \\
\hline \multirow{2}{*}{$\begin{array}{l}\text { Source of drinking } \\
\text { water }\end{array}$} & Spring & 1.00 & 1.00 & & \\
\hline & Well & $0.46(0.26-0.81)^{*}$ & $0.38(0.17-0.86)^{*}$ & & \\
\hline \multirow{2}{*}{ Latrine } & Available & & & 1.00 & 1.00 \\
\hline & Not available & & & $9.64(5.11-18.19)^{*}$ & - \\
\hline \multirow{3}{*}{$\begin{array}{l}\text { Hand washing near } \\
\text { the latrine }\end{array}$} & Present & & & 1.00 & 1.00 \\
\hline & Not present & & & $2.11(1.13-3.94)^{*}$ & $2.43(1.25-4.71)^{*}$ \\
\hline & In the pit & $0.38(0.17-0.87)^{*}$ & $0.38(0.17-0.86)^{*}$ & $1.19(0.52-2.75)$ & - \\
\hline \multirow{3}{*}{$\begin{array}{l}\text { Place of refuse/waste } \\
\text { dispose }\end{array}$} & $\begin{array}{l}\text { Open field (in the } \\
\text { compound) }\end{array}$ & $0.58(0.26-1.26)$ & $0.85(0.37-1.97)$ & $0.22(0.12-0.38)^{*}$ & - \\
\hline & $\begin{array}{l}\text { Open field (out of the } \\
\text { compound) }\end{array}$ & $3.12(1.08-9.05)^{*}$ & $2.14(1.03-4.45)^{*}$ & $0.69(0.22-2.18)$ & - \\
\hline & $\begin{array}{l}\text { Burning in the } \\
\text { compound }\end{array}$ & 1.00 & 1.00 & 1.00 & 1.00 \\
\hline \multirow{4}{*}{$\begin{array}{l}\text { Time of hand } \\
\text { washing } \\
\text { Detergent used for } \\
\text { hand washing }\end{array}$} & Mixed practices & $4.25(1.16-15.53)^{*}$ & - & $6.87(3.73-12.66)^{*}$ & - \\
\hline & At all critical time & 1.00 & 1.00 & 1.00 & 1.00 \\
\hline & only water & $2.93(1.60-5.38)^{*}$ & $2.46(1.27-4.75)^{*}$ & & \\
\hline & soap/ash & 1.00 & 1.00 & & \\
\hline
\end{tabular}

Note: $*$ =significantly associated $\mathrm{p}<0.05$

\section{Discussion}

Diarrheal diseases remain a major cause of morbidity and mortality in low-income like Ethiopia societies, and the aim of the present study was to assess the important CLTSH approach implementation on the prevention of diarrheal disease by comparing kebeles where the approach implemented and non-implemented.

In the study, the overall two weeks period prevalence of diarrhea in the CLTSH implemented and non-implemented kebeles were $18.91 \%$ and $22.22 \%$ respectively. The figure in the CLTSH non-implemented is high when compared with the figure in the CLTSH implemented kebeles. The difference in latrine coverage and utility, water source protection, and the difference in the using soap/ash might explain these variations.

Study showed that family size had impacts on the occurrence of diarrhea in the adjusted in both CLTSH implemented and none implemented kebeles. As the family size becomes increase, they might be overcrowded, which lead the family members to poor hygienic practice.

In this study the occurrence of diarrhea was statistically associated with the family size, source of water supply, place of waste disposal and detergent used for hand washing after latrine visit in the CLTSH implemented kebeles and family size and presence of hand washing facility near the latrine CLTSH none implemented kebeles in the bivariate and multivariate analysis. These variables might be the cause for the difference of diarrhea prevalence for the compared

\section{kebeles.}

Study showed that obtaining water from storage containers by dipping was a risk factor for diarrhea [7]. But in this study occurrence of diarrhea was not statistically significant with way of drawing water from storage in both bivariate and multivariate analysis; however the risk of the occurrence of diarrhea was 1.94 and 1.22 times higher in households where water is obtained from storage container by dipping than in those where water is obtained by pouring in the approach implemented and non-implemented kebeles respectively. This might be introducing hands and objects in to stored water were sources of contamination.

The finding of this study shows that $91.49 \%$ households of the CLTSH implemented and $87.90 \%$ households of the non-implemented kebeles had pit latrines. This result is less when comparing with the findings of RIPPLE in Mirab Abaya Woreda, the SNNPR, which shows the latrine coverage was $94 \%$ coverage [8]. But greater when comparing with the findings of the Ethiopia Demographic and Health Survey in 2011, which indicated that about $55 \%$ households of the rural areas had latrine facilities[5]. It was also better when comparing with study conducted in district of Bahir Dar Zuria (58.4\% [9]. and Kewotth woreda, Amhara Region (67.7\%) [10]. The findings of this study also shows that of the households lacked latrines, about $54.9 \%$ in CLTSH non-implemented and $41.67 \%$ in CLTSH implemented kebeles were practice open defecation during survey.

Study showed that the occurrence of diarrhoea was associated with the extent of latrine utilization [11]. In this 
study the occurrence of diarrhea was statistically associated with the extent of latrine utilization in the bivariate analysis in the CLTSH non-implemented kebeles [OR: 9.64, 95\%CI: (5.11-18.19)] but the significant was disappeared in the multivariate analysis. This might be even though the latrines present they defecate in open field.

This study showed that hand-washing facilities near the latrines in CLTSH implemented (73.06\%) was almost equal to that of CLTSH non-implemented kebeles (72.58\%). The study also indicated that from those households had latrine the habit of hand-washing after defecation in CLTSH implemented and none implemented kebeles were $99.48 \%$ and $95.97 \%$ respectively. This study was better when comparing with study conducted in East Hararghe, Kersa District, only about $5.1 \%$ of the households having latrines were washed their hands after defecation [12]. These large differences might be promotion of hand washing along with latrine construction by governments and NGOs time to time.

The presence of hand washing facilities near the latrines encourages the users to wash their hands after latrine use. However, in multivariate analysis, latrine provided with hand washing facility was related to the risk of diarrhea in CLTSH non-implemented kebeles. But the significance was not related to the risk of diarrhea in both bivariate and multivariate analysis in the approach implemented kebeles. This might be even though the facility was present there they use other water for Handwashing after defication.

The reveal that $61.70 \%$ of the households in CLTSH implemented and $52.50 \%$ of the households in CLTSH non-implemented kebeles explained that they disposed wastes in open pit. However, the present finding is relatively higher when compared with study conducted in Kersa woreda, Eastern Hararghe, which shows $26.5 \%$ disposed wastes in open pits [12].

The study showed that the average water consumption of CLTSH approach implemented and non-implemented kebeles were $8.05 \mathrm{~L} / \mathrm{C} /$ day \& $7.27 \mathrm{~L} / \mathrm{C} /$ day respectively. However, this study finding was almost similar when compared with study conducted in Mecha District of West Gojjam which showed that the average water consumption was $7.7 \mathrm{~L} / \mathrm{C} /$ day [13]. But the result was below the figures of south western Ethiopia which was $15.4 \mathrm{~L} / \mathrm{C} /$ day [14].

\section{Conclusion}

In the study the prevalence of diarrhea in the CLTSH non-implemented is high when compared with the figure in the CLTSH implemented kebeles. The study showed that the extent of latrine coverage and utilization in CLTSH implemented was greater than that of CLTSH non-implemented kebeles. The study indicated that both compared kebeles were not ODF even the approach implemented in three kebeles. In this study hand-washing facility near the latrines in CLTSH implemented kebeles $(73.06 \%)$ was greater than that of CLTSH non-implemented kebeles $(72.58 \%)$. The study also indicated that from those households with latrine the habit of hand-washing after defecation in CLTSH implemented was greater than the non-implemented kebeles but had no significant association in bivariate and multivariate analysis in both kebeles. Thus, it can be concluded that it is possible to reduce diarrheal disease through implementation of CLTSH approach.

\section{Recommendations}

Depending on the results of this study, the following recommendations are suggested:

Health-workers and local authorities must give health education and sensitization for the community to improve this open defecation.

Certification of the kebele should be based on the sustainability of the approach even in one year.

Authors' Contribution

NE: Conceptualized the research problem, designed the study, prepared the proposal, conducted field work, and analyzed the data, manuscript writing.

AB: Revised the proposal, participated in data analysis and the report revision.

GT: Revised the proposal, participated in data analysis and the report revision.

\section{Acknowledgement}

We would like to express our deepest appreciation to Jimma University, College of Public Health and Medical Sciences for providing us the opportunity to conduct this study and financial support to undertake the study in the study area.

\section{References}

[1] Jill W. Ahs, W. T. (2010). diarrheal diseases in low and middle-income countries. the open infectious diseases journal, 113-124

[2] WHO. (2004). The world health report 2004 - changing history. Retrieved http://www.who.int/whr/2004/en/report04_en.pdf

[3] Belachew, T. J. (2001). Module on diarrheal disease for the Ethiopian Health Center Team. Addis Ababa: Jimma University in collaboration with EPHTI, Carter Center, Ethiopia $\mathrm{MOH}$ and MOE,Ethiopia.

[4] Kenya Breaking Toilet Taboos. (2012, April 09). Retrieved from http://allafrica.com.

[5] Central Statistics Authority \& ORC Marco. (2011). Ethiopia Demographic and health survey (DHS). Central Statistics Authority. Addis Ababa, Ethiopia and Calverton, Maryland, USA.

[6] Lyla, M. \& Petra, B. (2009). Community-led total sanitation(CLTS) across the seas: Experiences from Africa witha special emphasis on Ethiopia. RiPPLE Working Paper 12. , p6

[7] Teklemariam, S., Getaneh, T. \& Bekele, F. (2000). Environmental determinants of diarrhoea morbidity in under-five children. Keffa-Sheka Zone. Southwest Ethiopia . Ethiop. Med. J. , 38(1): 27-34. 
676 Negasa Eshete et al.: Implementation of Community-led Total Sanitation and Hygiene Approach on the Prevention of Diarrheal Disease in Kersa District, Jimma Zone Ethiopia

[8] Tefera, W. (2008). Technical Issues of Sanitation and Hygiene in Mirab Abaya and Alaba; a case study report from the Southern Nations Region (SNNPR) of Ethiopia. RIPPLE Working Paper no.2.

[9] Awoke, W. \& Muche, S. (2013). latrine coverage and associated factors among rural communities inthe District of Bahir Dar Zuria, Ethiopia. BMC Public Health , 13:99.

[10] Rachael, R. (2011). An evaluation of household latrine coverage in Kewot woreda, Ethiopia three years after. Emory University.

[11] Anteneh, A. \& Kumie, A. (2010). Assessment of the impact of latrine utilization on diarrheal disease in the rural community of Hulet Ejju Enessie district, East Gojjam Zone, Amhara Regional state. Master thesis,. Ethiop. J. Health Dev. , 24(2);110-118.
[12] Mengistie, B. \& Baraki, N. (2010). Community based assessment on household management ofwaste and hygiene practices in Kersa Woreda, Eastern Ethiopia. Ethiop. J. Health Dev. , 24(2):103-109.

[13] Dessalegn, M. (2009). Does the effect of water and sanitation vary by maternal education on childhood diarrhea. Addis Ababa: Addis Ababa University..

[14] Wondimagegn, S. (1994). Survey of environmental sanitation in urban and rural communities in south western Ethiopia. Bull. JIHS , 4:40-51. 